\title{
ARTEMIA SALINA L. (ANOSTRACA): UMA OPÇÃO PARA A AQUICULTURA DO NORDESTE DO BRASIL
}

MARCOS ROGÉRIO CÂMARA EDISON VIEIRA DE CASTRO

\section{ABSTRACT}

Inoculations made with cysts of Artemia salina from San Francisco Bay (California, USA) in Macau, Rio Grande do Norte, Brazil, in 1977, have dispersed this crustacean in all neighboring salt work areas. Favourable environmental conditions which have successfully contributed to this inoculation, together with suggestions for a rational utilization of similar areas for Artemia salina cultivation, are analyzed and commented.

\section{INTRODUÇÃO}

A crescente demanda de cistos de Artemia salina, em contraste com o estacionário suprimento deste tipo de alimento, motivou tentativas das mais diversas para solucionar este problema, considerado já em 1976 ponto de estrangulamento para a aquicultura em todo o mundo (Sogerloos, 1976). As primeiras tentativas para inoculação de Artemia salina em ambientes naturais ocorreram no início da década de sessenta, nas lagunas hipersalinas da Ilha Christmas, no Pacífico Central (Helfrich, 1973) que, em razão de fatores ecológicos adversos, não foram bem sucedidas.

Resultados satisfatórios, através de inoculações temporárias, têm sido conseguidos em áreas de salina em países como Filipinas (Los Santos et al., 1980) e Tailândia (Vos \& Tansutapanit, 1979).

Em Macau, Nordeste do Brasil, a partir de inoculações feitas com cistos de Artemia salina importados da Califórnia, E.U.A. (origem comercial: San Francisco Bay Brand), em 1977, populações deste crustáceo se dispersaram por toda a região salineira do Rio Grande do Norte.

\section{DISCUSSÃO}

As favoráveis e peculiares condições ecológicas encontradas na região de Macau foram fundamentais na bem sucedida inoculação do crustáceo Artemia salina e sua consequente disseminação em toda área salineira adjacente. Basicamente, devem ser enfatizados os seguintes aspectos ecológicos, que contribuíram sobremaneira para que isto ocorresse:

1) Temperatura - A faixa de temperatura encontrada na região de Macau se situa entre o nível considerado ótimo para este crustáceo, que é de $25^{\circ} \mathrm{C}$ a $30^{\circ} \mathrm{C}$.

2) Salinidade - As elevadas salinidades (450/00 a $160 \% \%_{00}$ ) encontradas nos evaporadores das salinas, funcionam como barreira ecológica para organismos predatores e/ou competidores de Artemia salina.

3) Oxigênio - Ao suportar valores abaixo de $1 \mathrm{ml} / 1$, o crustáceo em estudo pode resistir aos baixos níveis de oxigênio dissolvido encontrados em águas hipersalinas.

4) Disseminação por pássaro - A grande quantidade de pássaros existente na região de Macau contribuiu para que este crustáceo se dispersasse, não apenas por transporte externo, como também por ingestão de alimento, uma vez que parte dos cistos ingeridos são excretados pelos pássaros, sem perder sua viabilidade. Por outro lado, a ausência de rotas de migração de pássaros 
ao longo da costa do Nordeste do Brasil impediu que uma maior distribuição geográfica deste crustáceo pudesse ter ocorrido.

5) Disseminação pelo vento - O relevo plano, característico das áreas de salina, contribuiu para uma maior dispersão de cistos através do vento.

6) Produtividade primária da área - Ao serem abastecidos por águas provenientes de área de mangue, a produtividade primária dos evaporadores iniciais das salinas é elevada a níveis que proporcionam o rápido e constante desenvolvimento das populações de Artemia salina.

A maioria das salinas existentes em toda a região do Nordeste apresentam aspectos ecológicos semelhantes aos acima citados, podendo, por conseguinte, serem aproveitadas, após pequenas modificações, como áreas de produção de Artemia salina. Isto poderá ser desenvolvido em consórcio com outras atividades econômicas, funcionando como fonte complementar de geração de recursos.

Estas transformações, e posteriores inoculações, devem obrigatoriamente estar embasadas em estudos ecológicos detalhados, sendo feitas sob orientação técnica especializada. Especial atenção deve sẹr dada à origem dos cistos usados em tais tentativas, evitando-se desse modo o aparecimento de espécies geneticamente indesejáveis. Em princípio, é nossa opinião que deve-se usar cistos provenientes da região de Macau, cujas populações de Artemia salina têm se mostrado bastante produtivas, apresentado seus cistos índices de eclosão, biomassa naupliar, conteúdo energético e pureza, que os colocam entre os mais aceitos a nível mundial (Vanhaecke et al., 1981).

Uma vez desenvolvidas atividades de cultivo de Artemia salina em número razoável em determinada área, a solução mais racional parece-nos ser a instalação de um único complexo de beneficiamento de cistos e artêmias adultas. Isto, não só devido ao alto custo de uma unidade deste tipo, como também pela necessidade de um eficaz controle de qualidade e escoamento de produção.

$\mathrm{Na}$ Salina São Pedro, em Macau, a produtividade de cistos de Artemia salina, no período posterior à sua inoculação, apresentou-se conforme os dados contidos no Quadro I, variando entre $1,04 \mathrm{~kg} / \mathrm{ha} /$ trimestre e 26,26 $\mathrm{kg} / \mathrm{ha} /$ trimestre.

QUADRO 1

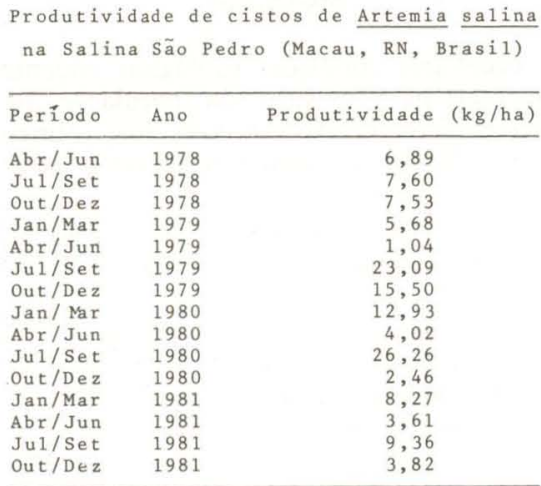

Um aumento na produtividade de cistos deste crustáceo, da mesma forma que a sua uniformização, está na dependência direta de um melhor conhecimento dos fatores que o levam a inverter seu mecanismo de reprodução, de ovoviviparidade para oviparidade, liberando os cistos. Este fenômeno ocorre quase que ao acaso, pois não dispomos de informações suficientemente consistentes que nos permitam interferir neste processo de maneira racional. 
A liofilização ou congelamento de artêmias adultas, para posterior uso como alimento para organismos aquáticos ou fonte de proteínas no preparo de rações animais, apesar de ser prática, ainda usada em pequena escala, é a solução indicada para uma mais completa utilização deste crustáceo.

\section{CONCLUSOES}

Tomando como referência os resultados obtidos em termos de produção de cistos de Artemia salina na Salina São Pedro, no período seguinte à sua inoculação (Quadro I), e levando em conta as diversas considerações feitas na discussão deste trabalho, conclui-se por:

1) Conversão de áreas de salina na região nordestina, presentemente abandonadas ou sub-aproveitadas, em áreas para cultivo em larga escala do crustáceo Artemia salina, consorciado com outras atividades econômicas.

2) Estudos visando conhecer detalhadamente a ecologia das áreas passíveis de conversão e a origem dos cistos a serem usados para tal fim.

3) Criação de unidades centrais para processamento de cistos e beneficiamento de indivíduos adultos por liofilização ou congelamento.

4) Conjugação de esforços, a nível nacional, para um melhor conhecimento do crustáceo Artemia salina, e mais especificamente, de sua ecologia, campo de estudo onde ocorre uma denotada escassez de literatura.

\section{REFERENCIAS}

Helfrich, P., 1973. The feasibility of brine shrimp production on Christmas Island. Sea Grant tech. Rep. UNIHI-SEA-GRANT, TR-73-02: 173 pp.

Los Santos, C. de, P. Sogerloos, E. Laviña \& A. Bernardino, 1980. Successful inoculation of Artemia and production of cysts in man-made salterns in the Philippines, pp. 159-163, in Persoone, G., P. Sogerloos, O. Roels \& E. Jaspers, eds., The brine shrimp Artemia. 3. Ecology, Culturing, Use in Aquaculture, 456 pp. Universa Press, Wetteren.

Sogerloos, P., 1976. The brine shrimp, Artemia salina: A bottleneck in mariculture? Pap. FAO tech. Conf. Aquaculture, Kyoto, May 26 - June 2, 1976.

Vanhaecke, P. \& P. Sogerloos, 1981. International study on Artemia. XIX. Hatching data on 10 commercial sources of brine shrimp cysts and re-evaluation of the "hatching efficiency" concept. Pap. Wld Mariculture Soc., Tech. Sess., Seattle, March 8-10, 1981.

Vos, J. \& A. Tansutapanit, 1979. Detailed report on Artemia cysts inoculation in Bangpakong, Cachoengsao Province. FAO/UNDP Field Doc. THA/75/ 008: $54 \mathrm{pp}$. 